\title{
Faktor yang Mempengaruhi Implementasi Green Human Resource Management pada Ormawa: Model Konseptual
}

\author{
Moch. Yusuf Fathussalam" ${ }^{* 1)}$ I G Ag Kom Agnam M.'), Irene Dyah Ayuwati³), Desy Fitri A. L.4), \\ Yuniar Revi A. L. ${ }^{5)}$, Geraldo Brata Hiroshi P. ${ }^{6}$, dan Ully Asfari ${ }^{7)}$ \\ ${ }^{1)}$ Sistem Informasi, Fakultas Teknologi Informasi dan Industri, Institut Teknologi Telkom Surabaya, Jl. \\ Ketintang No. 156, Surabaya, 60231, Indonesia

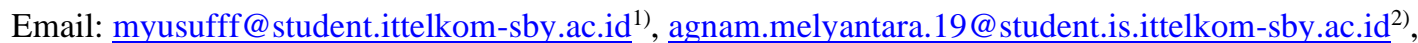 \\ irene.dyah.18@student.is.ittelkom-sby.ac.id ${ }^{3)}$, desy.fitri.19@student.is.ittelkom-sby.ac.id ${ }^{4)}$, \\ yuniar.revi.18@student.is.ittelkom-sby.ac.id ${ }^{5)}$, geraldo.brata.18@student.is.ittelkom-sby.ac.id ${ }^{6}$, \\ ully.asfari@ittelkom-sby.ac.id ${ }^{7)}$
}

\begin{abstract}
Abstrak
Pada era global warming, implementasi green human resource management diperlukan untuk meminimalisir kerusakan lingkungan. Green human resource management merupakan pengelolaan SDM secara berkelanjutan dengan memperhatikan aspek lingkungan. Penerapan praktik GHRM terhadap organisasi dianggap efektif dan memberikan umpan balik yang positif. Hal tersebut dilandasi oleh beberapa faktor. Ormawa (Organisasi Mahasiswa) adalah salah satu organisasi yang diharapkan dapat mengimplementasikan praktik GHRM. Sehingga praktik kesadaran lingkungan dapat diterapkan di kehidupan kampus. Penelitian ini bertujuan untuk memaparkan kerangka konseptual yang menggambarkan hubungan variabel determinan implementasi GHRM terhadap praktik implementasi GHRM untuk pengembangan SDM Ormawa yang berkelanjutan. Penelitian ini menggunakan metode pengumpulan data dengan multimethod research yang menyorot pengaruh faktor motivasi terhadap praktik GHRM. Dengan demikian, hasil penelitian diharapkan dapat membantu para pemangku kepentingan dalam meningkatkan motivasi anggota organisasi untuk menerapkan konsep GHRM demi pengembangan sumber daya yang berkelanjutan.
\end{abstract}

Kata kunci: Green Human Resource Management, Conceptual framework, Organisasi Mahasiswa.

\begin{abstract}
In the global warming era, the implementation of green human resource management is needed to minimalize the environmental issues. Green human resource management is the sustained human resource management by paying attention to environmental aspects. The implementation of GHRM practice towards organization is considered effective and provides positive feedback that based on several factors. Student organization is one of the organization that is expected to implement GHRM practices. So that environmental awareness practices could be applied in campus life. This research is aimed to presents a conceptual framework that describes the relationship between the determinant variables of GHRM implementation and GHRM implementation practices for sustainable human resource development in student organizations. This research using multimethod research approach which highlights the influence of motivational factors on GHRM practices. Thus, the results are expected to assist stakeholders in increasing the motivation of organizational members to apply the GHRM concept for sustainable resource development.
\end{abstract}

Keywordsi: Green Human Resource Management, Conceptual framework, Student Organization.

\section{Pendahuluan (Introduction)}

Permasalahan lingkungan merupakan salah satu masalah penting yang harus segera diselesaikan, khususnya di Indonesia. Mengingat kerusakan lingkungan dapat berdampak buruk bagi kelanjutan hidup manusia. Dengan demikian, dibutuhkan penerapan praktik pelestarian lingkungan dan pemberian wawasan akan pentingnya memelihara kondisi lingkungan. Green 
Human Resource Management (GHRM) adalah salah satu upaya yang dapat membantu dalam mengurangi dampak kerusakan lingkungan (Opatha and Arulrajah, 2014). Dimana pada penerapannya meliputi fungsi manajemen sumber daya manusia seperti proses rekrutmen dan seleksi, evaluasi kinerja, penghargaan, pelatihan dan pengembangan, hingga pemberdayaan SDM (Astuti and Wahyuni, 2018; (Masri and Jaaron, 2017)).

Menurut data Environment Performance Index (EPI), kualitas lingkungan di Indonesia berada pada urutan ke-116 dari total 180 negara, dan urutan ke-10 di Asia-Pasifik dengan nilai EPI sebesar 37.8 (Yale University, 2020). Dimana kita masih tertinggal jauh dengan Malaysia, Vietnam, dan Thailand yang notabenenya berstatus negara berkembang dan berada di urutan 100 besar. Dari hal tersebut, dapat dilihat bahwa kepedulian masyarakat akan kelestarian lingkungan masih rendah. Hal tersebut dapat didasari oleh kurangnya motivasi diri dalam berperilaku ramah lingkungan. Organisasi dianggap sebagai wadah yang efektif dalam mengimplementasikan praktik GHRM. Hal tersebut dilandasi oleh beberapa faktor yang mempengaruhi praktik implementasi GHRM seperti komitmen organisasi/pemimpin, aturan/regulasi yang ditetapkan, kesadaran anggota organisasi akan pentingnya berperilaku ramah lingkungan, penghargaan dan pelatihan yang diberikan, hingga tingkah laku pemimpin (Salim, Agus, 2017; Singh et al., 2020; (Jabbar and Abid, 2014)). Sehingga organisasi diharapkan dapat membantu menumbuhkan kesadaran akan etika lingkungan pada individu (Mishra, 2017; Romadhoni, Haryono and Nuryakin, 2019).

Implementasi praktik Green Human Resource Management telah banyak digunakan oleh berbagai sektor seperti industri manufaktur, kesehatan, pariwisata, UMKM, dll (Astuti and Wahyuni, 2018; Anwar et al., 2020; Ari et al., 2020). Selain itu, beberapa penelitian terdahulu juga menggunakan sektor-sektor tersebut sebagai studi kasus. Akan tetapi, terdapat celah terkait implementasi dan penelitian praktik GHRM pada institusi pendidikan. Dimana baik tingkat implementasi maupun penelitiannya masih terbilang rendah (Anwar et al., 2020). Padahal institusi pendidikan, khususnya perguruan tinggi, akan menjadi awal yang bagus dalam membangun kesadaran etika lingkungan. Hal tersebut dikarenakan pada pendidikan tingkat lanjut (perguruan tinggi) individu akan diajarkan kerangka berpikir kritis dan pengembangan diri melalui organisasi. Oleh karena itu, peneliti bermaksud mencari tahu apa saja faktor motivasi yang memiliki pengaruh terhadap implementasi praktik Green Human Resource Management pada organisasi. Penelitian ini diharapkan dapat membantu ormawa dalam pengimplementasian GHRM sehingga meningkatkan kesadaran etika lingkungan khususnya pada mahasiswa (individu).

\section{Metode Penelitian (Methods)}

Penelitian ini menggunakan metode analisis deskriptif serta pendekatan multimethod research yang memerlukan dua atau lebih sumber data untuk menyelidiki pernyataanpernyataan terkait (Hunter and Brewer, 2016). Dimana sumber literasi didapatkan dari perangkat pencarian seperti Scholar, Scopus, Emerald Insight, dan Elsevier dengan penggunaan kata kunci GHRM, conceptual framework, dan motivation theory. Penelitian ini melalui beberapa proses seperti yang ada pada gambar di bawah ini:

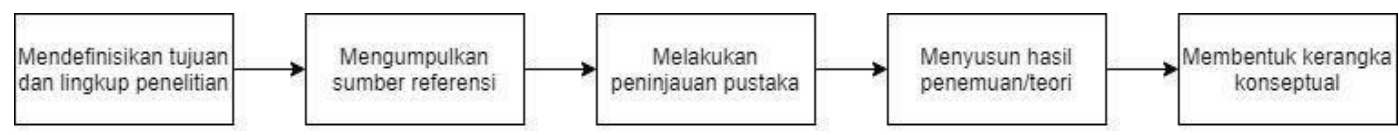

Gambar 1. Langkah-Langkah Penelitian 


\section{Hasil dan Pembahasan (Results and Discussions)}

\subsection{Green Human Resource Management}

Menurut teori Triple Bottom Line (TBL) yang dikemukakan oleh John Elkington, dalam mempertahankan sebuah organisasi, terdapat tiga aspek yang perlu diperhatikan yaitu keuntungan (profit), pemangku kepentingan (people), dan lingkungan (planet) (Salim, Agus, 2017). Akhirakhir ini, Green Human Resource Management menjadi tren terkait dengan meningkatnya kerusakan lingkungan. Selain bermanfaat bagi lingkungan, beberapa penelitian menyatakan penerapan GHRM juga bermanfaat bagi organisasi. (Rani and Mishra, 2014) menyatakan bahwa dengan penerapan GHRM, organisasi dapat menurunkan biaya pengeluaran, meningkatkan pandangan sosial, dan menyediakan suasana kerja yang kondusif. Pada (Salim, Agus, 2017) dijelaskan bahwa implementasi GHRM memberikan manfaat berupa peningkatan retensi anggota, peningkatan produktivitas, serta peningkatan daya saing dan kinerja secara keseluruhan. Proses implementasi praktik GHRM tentunya tidak lepas dari peran MSDM. Salah satunya adalah dengan mendapatkan dukungan anggota dalam mengimplementasikan perilaku ramah lingkungan seperti penggunaan kendaraan umum, daur ulang, dan pelestarian energi terbarukan (Rani and Mishra, 2014). Tentunya proses ini tidak akan mudah. Mengingat organisasi juga harus memberikan dan mengetahui teknik motivasi yang tepat bagi para anggotanya serta menganalisis faktor-faktor yang dapat mempengaruhi motivasi kerja anggota. Sehingga kinerja anggota akan selaras dengan tujuan organisasi dalam menumbuhkan kesadaran etika lingkungan.

\subsection{Faktor yang Mempengaruhi Implementasi praktik GHRM}

\subsubsection{Sistem Penghargaan dan Motivasi Kerja (Reward System and Job Motivation)}

Kinerja anggota adalah hal yang paling penting bagi suatu organisasi karena dapat membantu mengukur tujuan dan objektif organisasi (Pang and Lu, 2018). Idowu (2017) dalam (Tarmidia et al., 2019) menyatakan bahwa kinerja adalah hasil dari kualitas maupun kuantitas yang dicapai anggota dalam melaksanakan tanggung jawab atau kewajibannya. Menurut Venkarta and Ramanujam (1986) dalam (Pang and Lu, 2018), kinerja finansial (investasi, pendapatan, dll), kinerja operasional (kualitas produk, pangsa pasar, dll), serta efektifitas organisasi (moral anggota, suasana kerja, dll) merupakan faktor yang digunakan untuk mengukur kinerja organisasi. Lawler (2005) dalam (Pang and Lu, 2018) menyatakan bahwa sistem motivasi yang tepat akan meningkatkan efisiensi dan kualitas kinerja. Rukmana et al. (2018); Julianry et al. (2017); dan Sandhu (2017) dalam (Tarmidia et al., 2019) juga membuktikan bahwa motivasi kerja memiliki hasil positif dan pengaruh signifikan terhadap kinerja anggota dalam praktik GHRM.

Dari penelitian yang dilakukan oleh (Pang and Lu, 2018), motivasi diartikan sebagai mekanisme internal yang berperan sebagai katalisator bagi individu untuk meningkatkan kinerja. Tujuan dari motivasi itu sendiri adalah untuk meningkatkan produktivitas, efisiensi, dan keseluruhan kinerja organisasi. Oleh karena itu, penting bagi organisasi untuk mengetahui faktor-faktor yang dapat memotivasi anggota untuk mengerjakan tugas mereka dengan maksimal. Beberapa bentuk motivasi tersebut dapat berupa insentif, keamanan kerja, promosi, kondisi kerja hingga apresiasi dari atasan (Islam and Ismail, 2008; Kubo and Saka, 2005; AlAlawi, 2005). Sistem penghargaan dianggap dapat memberikan dorongan kepada anggota untuk melakukan upaya ekstra (pekerjaan) dalam memenuhi permintaan organisasi (implementasi praktik GHRM) sehingga dapat menyelaraskan antara kinerja anggota dan tujuan organisasi dalam menerapkan perilaku ramah lingkungan (Mishra, 2017). 


\subsubsection{Budaya Organisasi dan Kepuasan Kerja (Organizational Culture and Job Satisfaction)}

Selain sistem motivasi yang tepat, hasil yang berbeda dikemukakan pada penelitian yang dilakukan oleh Cupiadi \& Kedaton (2016); Nuryaman \& Suryaman (2018); dan Jondar \& Sudarsono (2015) dalam (Tarmidia et al., 2019) yang menyatakan bahwa kultur organisasi memiliki pengaruh signifikan positif dan secara signifikan mempengaruhi terhadap kinerja anggota terhadap praktik penerapan GHRM. Sedangkan menurut publikasi Wu et al. (2003); Shiu and Yu's (2010), tingkat kepuasan kerja memiliki hubungan signifikan positif dengan kinerja organisasi. Hal tersebut dikarenakan oleh kepuasan kerja dapat menimbulkan perilaku positif serta komitmen anggota terhadap pekerjaannya sehingga dapat meningkatkan kinerja organisasi. Lockey (1975) dan Parvin and Kabir (2011) dalam (Pang and Lu, 2018) mendefinisikan kepuasan kerja sebagai emosi positif yang dirasakan oleh individu dari pengalaman kerja yang memuat aspek motivasi, kinerja, kepemimpinan, tingkah laku, konflik, dan sebagainya.

\subsubsection{Regulasi dan Komitmen Organisasi (Regulation and Organizational Commitment)}

Hasil penelitian Zaman (2012) dalam (Salim, Agus, 2017) pada perusahaan manufaktur di Malaysia menunjukkan bahwa regulasi merupakan penentu yang dapat menjelaskan komitmen perusahaan dalam etika lingkungan. Sementara itu, hasil penelitian Yusoffet et, al. (2015) dalam (Salim, Agus, 2017) menunjukkan bahwa regulasi merupakan konsep yang terkait dengan pelaksaan praktik GHRM. Selain regulasi, komitmen organisasi juga dinilai penting dalam implementasi praktik GHRM. Hasil penelitian Erdogan et, al. (2015) dalam (Salim, Agus, 2017) menunjukkan adanya pengaruh komitmen organisasi terhadap perilaku ramah lingkungan. Arygris (1998) dalam (Jabbar and Abid, 2014) mendefinisikan komitmen organisasi sebagai cara pengaktifan pikiran dan energi pada tiap individu untuk membantu tujuan organisasi dalam menerapkan perilaku ramah lingkungan. Studi yang dilakukan Ramus, 2001; Govindarajulu and Daily, 2004 menyatakan bahwa komitmen organisasi secara signifikan memoderasi dampak positif dari perilaku pemimpin terhadap motivasi anggota.

\subsubsection{Kesadaran Etika Lingkungan dan Perilaku Pemimpin ( Environmental Ethical Awareness and Supervisor Behaviour)}

Keraf 2010 dalam (Salim, Agus, 2017) menyebutkan bahwa masalah lingkungan adalah masalah moral dan bukan semata-mata persoalan teknis saja. Oleh karena itu, diperlukan adanya etika terhadap lingkungan hidup. Etika lingkungan hidup adalah disiplin ilmu yang mengatur perilaku manusia dengan lingkungan alam yang dapat diwujudkan dalam regulasi formal maupun gerakan-gerakan masyarakat. Dimana etika dalam lingkungan dapat diterapkan jika pemimpin juga ikut andil dalam membantu. Merujuk pada penelitian yang dilakukan Ramus and Steger's (2000) dalam (Jabbar and Abid, 2014), dukungan pemimpin sangatlah penting untuk memotivasi anggota organisasi terhadap praktik ramah lingkungan melalui eco-initiative.

\subsubsection{Pelatihan Lingkungan (Enviromental Training)}

Motivasi tidak akan cukup dalam membantu implementasi praktik GHRM. Karena jika SDM tidak memiliki pengetahuan dan kemampuan dasar untuk menerapkan praktik GHRM, maka mereka tidak mungkin dapat meningkatkan kinerja lingkungan organisasi. Menurut Cole (2008) dalam (Jabbar and Abid, 2014), pelatihan memiliki dampak positif terhadap kinerja lingkungan organisasi. Sementara itu Nawangsari dan Sutawidjaja (2018) dalam (Purnama and Nawangsari, 2019) menjelaskan bahwa pelatihan dapat membantu anggota organisasi dalam memahami pentingnya perlindungan lingkungan lebih lanjut. 
Dari hasil studi literasi, maka dapat diperoleh beberapa hipotesis sebagai berikut:

Tabel 1. Hipotesis

\begin{tabular}{|c|c|c|}
\hline Hipotesis & Hasil Penelitian & Referensi \\
\hline H1 & $\begin{array}{l}\text { Sistem penghargaan berpengaruh secara } \\
\text { signifikan terhadap kinerja dan motivasi } \\
\text { anggota organisasi dalam implementasi praktik } \\
\text { GHRM }\end{array}$ & $\begin{array}{l}\text { (Mishra, 2017), (Islam and } \\
\text { Ismail, 2008; Kubo and Saka, } \\
\text { 2005; Al-Alawi, 2005) }\end{array}$ \\
\hline $\mathbf{H} 2$ & $\begin{array}{l}\text { Budaya organisasi berpengaruh secara } \\
\text { signifikan terhadap kinerja anggota organisasi } \\
\text { dalam implementasi praktik GHRM }\end{array}$ & $\begin{array}{l}\text { Cupiadi \& Kedaton (2016); } \\
\text { Nuryaman \& Suryaman (2018); } \\
\text { dan Jondar \& Sudarsono (2015) } \\
\text { dalam (Tarmidia } \text { et al., 2019) }\end{array}$ \\
\hline H3 & $\begin{array}{l}\text { Kepuasan kerja berpengaruh signifikan } \\
\text { terhadap kinerja anggota organisasi dalam } \\
\text { implementasi praktik GHRM }\end{array}$ & $\begin{array}{l}\text { Wu et al. (2003); Shiu and Yu's } \\
\text { (2010) }\end{array}$ \\
\hline H4 & $\begin{array}{l}\text { Etika terhadap lingkungan berpengaruh secara } \\
\text { signifikan terhadap kinerja anggota organisasi } \\
\text { dalam implementasi praktik GHRM }\end{array}$ & (Salim, Agus, 2017) \\
\hline H5 & $\begin{array}{l}\text { Perilaku pemimpin berpengaruh secara } \\
\text { signifikan terhadap motivasi anggota } \\
\text { organisasi dalam implementasi praktik GHRM }\end{array}$ & $\begin{array}{l}\text { Ramus and Steger's (2000) } \\
\text { dalam (Jabbar and Abid, 2014) }\end{array}$ \\
\hline H6 & $\begin{array}{l}\text { Komitmen organisasi secara signifikan } \\
\text { memoderasi dampak positif dari perilaku } \\
\text { pemimpin terhadap motivasi anggota }\end{array}$ & $\begin{array}{l}\text { Erdogan et, al. (2015) dalam } \\
\text { (Salim, Agus, 2017) }\end{array}$ \\
\hline H7 & $\begin{array}{l}\text { Regulasi merupakan faktor penentu dari } \\
\text { komitmen organisasi }\end{array}$ & $\begin{array}{l}\text { Zaman (2012) dalam (Salim, } \\
\text { Agus, 2017) }\end{array}$ \\
\hline H8 & $\begin{array}{l}\text { Pelatihan memiliki dampak positif terhadap } \\
\text { implementasi praktik GHRM serta secara } \\
\text { signifikan memoderasi motivasi anggota }\end{array}$ & $\begin{array}{l}\text { Cole (2008) dalam (Jabbar and } \\
\text { Abid, 2014) }\end{array}$ \\
\hline
\end{tabular}


Sehingga terbentuk kerangka konseptual sebagai berikut:

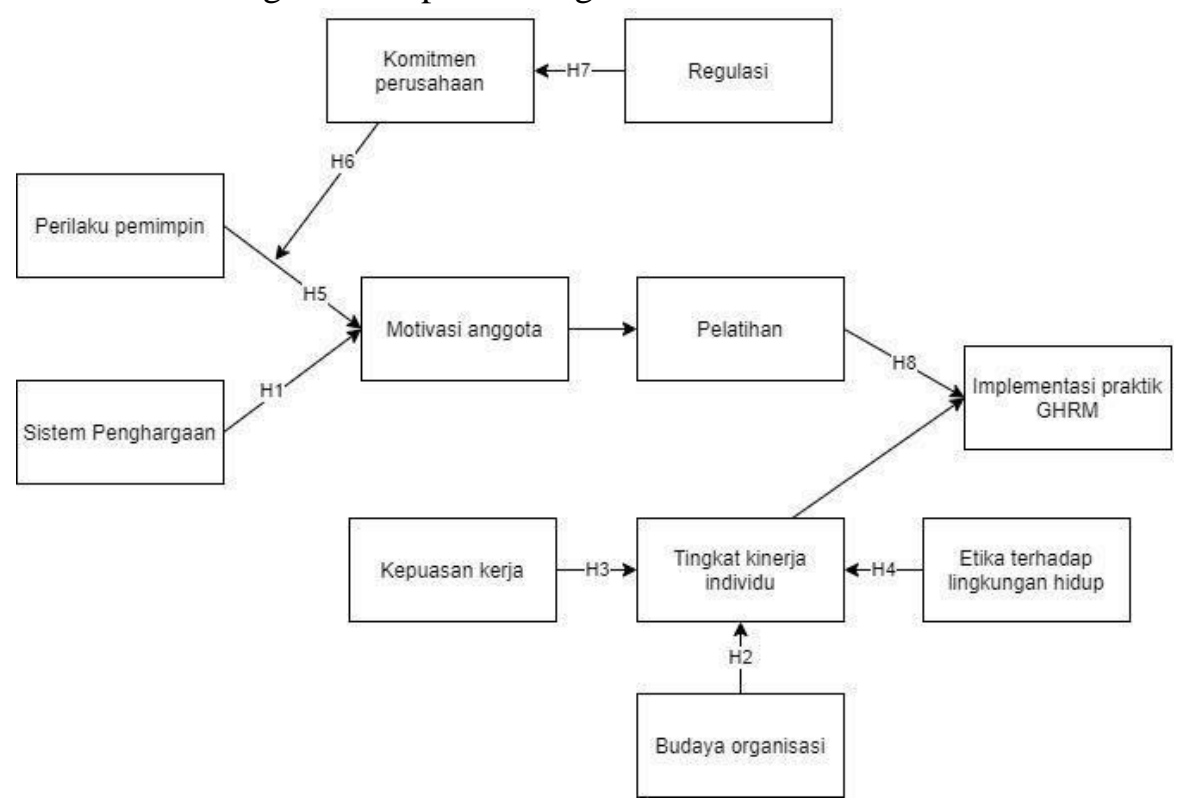

Gambar 2. Kerangka Konseptual

\section{Kesimpulan (Conclusion)}

Dalam praktik implementasi GHRM terdapat beberapa faktor yang mempengaruhi mulai dari motivasi anggota, pelatihan, kepuasan kerja, budaya organisasi, etika terhadap lingkungan. Dan beberapa faktor memiliki faktor dasar. Seperti motivasi anggota yang didasari oleh perilaku pemimpin terhadap anggotanya dan juga sistem penghargaan yang diberikan organisasi.

\section{Ucapan Terima Kasih (Acknowledgement)}

Pada kesempatan kali ini, penulis mengucapkan terimakasih kepada Ibu Ully Asfari S.Kom., M.Kom. selaku dosen pembimbing dan pengampu mata kuliah Manajemen Sumber Daya Manusia. Penulis juga berterimakasih kepada pihak yang telah membantu dalam penelitian ini.

\section{Daftar Pustaka}

Anwar, N. et al. (2020) 'Green Human Resource Management for organisational citizenship behaviour towards the environment and environmental performance on a university campus', Journal of Cleaner Production. Elsevier Ltd, 256, p. 120401. doi: 10.1016/j.jclepro.2020.120401.

Ari, E. et al. (2020) 'A conceptual model for green human resource management: Indicators, differential pathways, and multiple pro-environmental outcomes', Sustainability (Switzerland), 12(17). doi: 10.3390/su12177089.

Astuti, M. and Wahyuni, H. C. (2018) 'Strategi Implementasi Green Human Resource Management Pada Usaha Mikro, Kecil Dan Menengah (Umkm)', Matrik : Jurnal Manajemen, Strategi Bisnis dan Kewirausahaan, p. 121. doi: 10.24843/matrik:jmbk.2018.v12.i02.p04.

Mishra, P. (2017) 'Green human resource management: A framework for sustainable organizational development in an emerging economy', International Journal of Organizational Analysis, 25(5), pp. 762-788. doi: 10.1108/IJOA-11-2016-1079.

Opatha, H. H. D. N. P. and Arulrajah, A. A. (2014) 'Green Human Resource Management: Simplified General Reflections', International Business Research, 7(8), pp. 101-112. doi: 10.5539/ibr.v7n8p101. 
Romadhoni, E. F., Haryono, S. and Nuryakin (2019) 'Peran Faktor Sumber Daya Manusia Terhadap Praktik Sumber Daya Hijau (Studi Kasus PT Sarihusada Generasi Mahardika Yogyakarta)', NCAB (National Conference on Applied Business), pp. 115-118. Available at: https://www.unisbank.ac.id/ojs/index.php/ncab/article/download/7698/2659.

Salim, Agus, D. (2017) 'PROS_Agus S, Lieli S_Model implementasi green human_fulltext.pdf'.

Singh, S. K. et al. (2020) 'Green innovation and environmental performance: The role of green transformational leadership and green human resource management', Technological Forecasting and Social Change. Elsevier, 150(September 2019), p. 119762. doi: 10.1016/j.techfore.2019.119762.

Yale University (2020) 2020 EPI Results. Available at: https://epi.yale.edu/epi-results/2020/component/epi (Accessed: 18 January 2021).

Jabbar, M. H. and Abid, M. (2014) 'GHRM : Motivating Employees towards Organizational Environmental Performance', MAGNT Research Report, 2(4), pp. 267-278. Available at: https://www.researchgate.net/publication/281448584.

Masri, H. A. and Jaaron, A. A. M. (2017) 'Assessing green human resources management practices in Palestinian manufacturing context: An empirical study', Journal of Cleaner Production, 143, pp. 474-489. doi: 10.1016/j.jclepro.2016.12.087.

Hunter, A. and Brewer, J. D. (2016) Oxford Handbooks Online Conundrums of Multimethod Research Historical Development — The Initial. doi: 10.1093/oxfordhb/9780199933624.013.13.

Kubo, I. and Saka, A. (2002), "An inquiry into the motivation of knowledge workers in the Japanese financial industry”, Journal of Knowledge Management, Vol. 6 No. 3, pp. 262-271

Islam, R. and Ismail, A.Z.H. (2008), "Employee motivation: Malaysian perspective”, International Journal of Commerce and Management, Vol. 18 No. 4, pp. 344-362.

Al-Alawi, A.I. (2005), "Motivating factors on information technology employees in Bahrain hotel industry", Issues in Information Systems, Vol. 1 No. 2, pp. 112-115.

Wu, W.Y., Tsai, C.C. and Fu, C.S. (2013), "The relationships among internal marketing, job satisfaction, relationship marketing, customer orientation, and organizational performance: an empirical study of TFT-LCD companies in Taiwan", Human Factors and Ergonomics in Manufacturing \& Service Industries, Vol. 23 No. 5, pp. 436-449.

Shiu, Y.M. and Yu, T.W. (2010), "Internal marketing, organizational culture, job satisfaction, and organizational performance in non-life insurance", The Services Industries Journal, Vol. 30 No. 6, pp. 793-809.

Pang, K. and Lu, C. S. (2018) 'Organizational motivation, employee job satisfaction and organizational performance: An empirical study of container shipping companies in Taiwan', Maritime Business Review, 3(1), pp. 36-52. doi: 10.1108/MABR-03-2018-0007.

Rani, S. and Mishra, K. (2014) 'Green HRM : Practices and Strategic Implementation in the Organizations', International Journal on Recent and Innovation Trends in Computing and Communication, 2(11), pp. 3633-3639.

Tarmidia, D. et al. (2019) 'The effect of organizational culture and work stress on employee performance', International Journal of Innovation, Creativity and Change, 6(12), pp. 144-160. 
Purnama, N. D. and Nawangsari, L. C. (2019) 'Pengaruh Green Human Resource Management Terhadap Sustainability Business : Pendekatan Konsep The Effect of Green Human Resource Management Against Sustainability Business ':, pp. 32-39. 